\title{
DESIGN CONTEMPORÂNEO E O RESGATE DA MEMÓRIA: PROJETO INTERDISCIPLINAR
}

\author{
Mônica Moura \\ Universidade Estadual Paulista "Júlio de Mesquita Filho" - FAAC \\ monicamoura.design@gmail.com \\ Ana Beatriz Pereira de Andrade \\ Universidade Estadual Paulista "Júlio de Mesquita Filho" - FAAC \\ anabiaandrade@faac.unesp.br \\ Marina Jardim Tarozzo \\ Universidade Estadual Paulista "Júlio de Mesquita Filho" - FAAC \\ marinajtarozzo@gmail.com \\ Izabela Muniz Ambiel \\ Universidade Estadual Paulista "Júlio de Mesquita Filho" - FAAC \\ Izabela.m.ambiel@gmail.com
}

Resumo: Este artigo apresenta e discute a questão e a importância do resgate da memória em um projeto interdisciplinar na ação de ensinoaprendizagem aplicado sob o enfoque da resolução de problemas relacionados à criação e a autoria na formação superior em design na contemporaneidade em uma estrutura que relacionou discussões teóricas, desenvolvimento de levantamentos e pesquisa, reflexões, processo de desenvolvimento projetual em design editorial, experimentos artesanais e digitais, produção de livros autorais e independentes e cujos resultados foram reunidos em um acervo, expostos em mostra de caráter permanente em um web-site e tornaram-se objeto de estudo e análises destinados a educação dos futuros designers sem perder de vista sua constituição como sujeitos atuantes conscientes dos aspectos humanos e sensíveis.

Palavras-chave: Design Contemporâneo, Memória, Autoria, Ensino, Interdisciplinaridade.

\begin{abstract}
This article presents and discusses the questions and the importance of memory rescue in an interdisciplinary project on the action of teaching and learning applied in the problem solving approach related to the creation and authorship in the education of design in contemporary times in a structure related theoretical discussions, development of surveys and research, reflections, design development process in editorial design, craft and digital experiments, production of copyright and independent books and whose results were gathered in a collection, exhibited in permanent show on a web-site and became an object of study and analysis for the education of future designers without losing sight of its constitution as subjects active aware of the human and sensitive aspects.
\end{abstract}


Key-words: Contemporary Design, Memory, Authorship, Education, Interdisciplinarity.

\section{INTRODUÇÃO}

As questões relacionadas à identidade, memória e autoria têm sido cada vez mais estudadas, discutidas e pesquisadas, bem como têm sido aplicadas nos ambientes educacionais, em seus vários níveis, devido as possibilidades de amplitude na formação e na conscientização dos valores relacionados ao ser humano e destacando que os aspectos relacionados a identidade, memória e autoria ganham importância na contemporaneidade.

Pode até parecer uma contradição, mas é justamente nesse tempo marcado pela intensidade de informações aceleradas existentes nas redes, em conexões e nos diversos caminhos de acessos às linguagens e narrativas que o individual, as histórias pessoais, as situações singulares, as interpretações e visões próprias crescem em importância e valor. Provavelmente porque diante do excesso de informações passa a ser gerada tanta desinformação e passa a ocorrer a necessidade e a presença do resgate e da consequente valorização da memória em ações que abrem caminhos para a busca do que é mais significativo, singular e perene na vida cotidiana. Por outro lado, o crescimento das doenças emocionais e neurológicas, também denominadas de "doenças contemporâneas", tais como o mal de Alzheimer, as demências, depressões, síndrome do pânico, entre outras, tornam-se muito presentes e recorrentes levando as pessoas acometidas por essas doenças a perder pequenas ou grandes partes da memória. Diante dessa realidade e, até talvez, em contrapartida ao enfrentamento da mesma, várias pessoas, instituições e organizações (museus, ONGs, entre outros) passaram a explorar e valorizar o resgate da memória, das experiências vividas, dos laços familiares, dos fatos corriqueiros e cotidianos. E, também, diante dos processos globalizatórios ocorreu uma reação que gerou a valorização das identidades locais, estimulando o resgate das memórias individuais e coletivas.

Diante deste cenário e no âmbito do Laboratório de Pesquisa, Extensão e Ensino em Design Contemporâneo da UNESP de Bauru desenvolvemos a partir de 2013 um projeto interdisciplinar que passou a ser aplicado com a proposta de colaborar para a formação em design gráfico no segmento de design editorial pautado nas questões da autoria, da memória pessoal e familiar que resulta em um livro autoral na vertente das publicações independentes.

Essa pesquisa foi desenvolvida tendo como objetivo principal investigar a questão da memória no design contemporâneo estabelecendo relações e análises dos resultados da aplicação do projeto interdisciplinar "memórias da minha vida traduzidas em produto editorial".

O principal referencial teórico adotado neste recorte temático associa as áreas de design, educação, filosofia, psicologia social, história contemporânea e literatura a partir das obras de Poynor (2003), Couto (2011), Bergson (1999), Hobsbawm (2008), Pandolfi (2013), Ades (2004), Bosi (2003), Moura (2014), Telles (2009), Marquez (2003), Hatoum (2013), entre outros.

A metodologia adotada é de abordagem qualitativa a partir da revisão de literatura associada a estudos de caso, pesquisa documental e de campo. 


\section{DESENVOLVIMENTO}

A memória se faz presente em várias expressões e, assim atua diretamente na sensibilidade humana e colabora com os processos de criação e de projetação. A música "Depois" (2011) de Marisa Monte, de forma poética, reforça a importância da memória da seguinte maneira: "Nós fizemos história para ficar na memória e nos acompanhar". Na literatura encontramos vários autores que discutem ou que utilizam a memória como caminho de expressão. Em Telles (2009) a memória se mistura a invenção sem limites precisos. "Chão de infância. Nesse chão de lembranças movediças estão fixadas minhas pajens, aquelas meninas que minha mãe arrebanhava para cuidarem desta filha caçula." A infância é um lugar importante para a vida em distintos momentos onde as lembranças são resgatadas e associadas a tantos outros tempos da vida. Hatoum (2013) escreve "Há poucos dias visitei uma casa na Rua Saldanha Marinho, no centro de Manaus, que é também o centro de minha infância e, portanto, da minha memória." Fróes (2011) ao escrever a resenha do livro "Sardenha como uma infância" de Ellio Vittorini indica "É um texto jovem. Vittorini tinha vinte e quatro anos quando o escreveu. Estava assim a poucos passos da infância, e é por isso que as cenas que vivenciou na Sardenha despertam-lhe a toda hora o menino que ainda o acompanhava por dentro."

Abbagnano (1998) afirma que a memória é constituída por duas condições ou momentos distintos: a conservação e a recordação. A conservação diz respeito à persistência de conhecimentos passados, é denominada de memória retentiva. A recordação é a capacidade e a possibilidade de evocar o conhecimento do passado e de torná-lo atual ou presente. Para Bergson (1999), a memória é um progresso do passado ao presente em um estado agente que é a recordação.

A partir das reflexões acima podemos apontar que a memória pode ser retentiva ou recordativa. A primeira é constituída pela conservação de sensações, de conhecimentos. A segunda diz respeito às recordações, as reminiscências e tem o caráter ativo da escolha. Portanto, a memória diz respeito às histórias pessoais ou coletivas, as lembranças e recordações, aos vestígios, marcas, sensações e percepções, vivências, incluindo-se aí os ritos de passagem e os hábitos cotidianos. Assim sendo, a memória inter-relaciona as lembranças e o passado resgatando-os ao presente, mas associando a eles novas informações, ou seja, a memória nunca é isenta e não mantém a situação, a lembrança intacta ou exatamente da forma como ela foi vivida. Ao lembrarmos, associamos novos conhecimentos, novas percepções, interpretações e novas informações ao fato lembrado. Portanto, a memória não é isenta de interlocuções e é muito criativa. Ao lembrarmos-nos de algo ou de uma situação acionamos não apenas o cognitivo, mas também o emocional, que é somado às nossas atuais experiências de vida. Dessa forma, entrelaçamos o passado vivido às nossas convicções e à nossa existência no presente. A memória diz respeito aos conhecimentos e vestígios do passado que já estiveram disponíveis, às recordações que trazidas ao presente se somam a outros olhares. Evocamos a recordação e a tornamos presente.

A memória também pode ser entendida como marcas na e da alma que se movem entre a conservação, a persistência e as recordações. Podemos dizer que essas relações se estabelecem de maneira íntima e afetiva aos nossos pensamentos, ideias, lembranças, fagulhas de sensações que se constituem como representações e 
constroem a personalidade e a identidade a partir do reconhecimento do já visto e vivenciado.

Mas as memórias também têm a ver com a ativação da sensibilidade, tanto por parte do criador ou do designer quanto a do leitor, observador ou usuário. Em Viver para Contar (2003), Gabriel Garcia Marquez, inicia a obra com a seguinte epígrafe: " $A$ vida não é o que a gente viveu, e sim a que a gente recorda, e como recorda para contá-la".

Ades (2004) aponta que o resgate, a recuperação de aspectos do passado, da vida e dos momentos se configuram como narrativas, pois ao ativar as nossas lembranças a partir das nossas memórias criamos e contamos histórias a nós mesmos. Mas, ao relatarmos essas lembranças a outras pessoas passamos a estabelecer a cumplicidade.

\footnotetext{
"Mas o relato primordial é o que pode ser feito a outras pessoas: através dele, o que vivemos e que é bem nosso ganha uma dimensão social, obtém testemunhas (mesmo que a posteriori), faz com que os outros ampliem sua experiência, através das nossas palavras. Há troca e cumplicidade. Viver, para Contar (a vida), o título das memórias de Gabriel García Márquez, serve para todos nós. Viver algo notável gera a necessidade de contar: você sabe o que eu vi? você sabe o que me aconteceu? E tudo o que nos acontece é notável porque nos concerne." (ADES, 2004, p. 1)
}

As expressões trazidas nesse artigo como exemplos do resgate e do papel das memórias estimulam a sensibilização para os estudos e análises relacionados à memória e a criação. Podemos observar que quando a memória é resgatada ela se transforma em potência entre a ação e o ser criador, seja ele escritor, poeta, artista, designer.

As lembranças servem como um estímulo para despertar nossa atenção, sensação e percepção a respeito da importância da memória, daqueles momentos e instantes que, por pareceram tão comuns e cotidianos não os valorizamos no momento em que os vivemos, mas que à distância, com o passar do tempo, tornam-se essenciais na constituição de nossa identidade e de nossa alteridade. $E$, também, essência para nossas referências ou inspirações destinadas à criação, ao desenvolvimento projetual, que, ao resgatarem o passado se transformam em projetos no presente e em objetos expressivos e poéticos no futuro. Sejam estes objetos produtos de diferentes naturezas, escalas e tecnologias para as mais diferentes necessidades que envolvem a vida do ser humano. E, retomar a memória, as lembranças, as histórias pessoais, as histórias de vida é uma forma de construir ou expandir o seu eu e de compreender o outro, o ser humano que está ao nosso lado e que também assume o papel de sujeito-usuário na esfera do design.

\subsection{Memórias na Ação Criadora}

"A aparição do designer como autor é uma das ideias chave do design gráfico pós-moderno" (Poynor:2003,p.118). Podemos dizer que esse aspecto não fica restrito ao design gráfico e se estende a todos os segmentos de design.

Sabemos que um autor é aquele que dá origem a criação, invenção ou instituição de algo. No design contemporâneo os criadores, os autores tornaram-se centros de atenção e destaque na mídia, nas premiações e nas exposições e, também, foco de estudos acadêmicos e científicos. Evidência também pronunciada pelas 
dinâmicas de mercado com resultados significativos na autoria, nos valores de seus projetos, obras e objetos que passam a incorporar e destacar a assinatura de seu autor.

Poynor (2003) também destaca que o ato de desenhar, de projetar nunca é algo neutro e os designers, especialmente nos últimos 30 anos, sempre trazem algo de pessoal em seus projetos e têm sido considerados os profissionais mais significativos da cultura contemporânea, onde a memória assume papel significativo.

Nas últimas décadas pudemos observar em várias palestras de designers estrangeiros, tanto no Brasil quanto no exterior, que a maioria deles começava contando sua história de vida, quem era, onde nasceu, como era sua família, seus brinquedos e brincadeiras favoritas e o que isso tinha a ver com sua atuação em design. Esse discurso era permeado por fotos, músicas, objetos e ambientes antigos, geralmente da infância do palestrante.

Também, podemos inferir que o acesso aos diversos tipos de informação que circulam nas redes digitais fragilizou a criação de maneira geral. Muitas coisas são criadas e disseminadas rapidamente e os acessos e processos a diversos tipos de criação foram facilitados e massificados. Nessa situação a autoria e a inovação também ganharam destaque. Mas, como criar e inovar a partir de informações e referências diferenciadas? Passou a ganhar maior valor àquilo que é único, pessoal, algumas vezes até íntimo. Uma das maneiras é buscar aquilo que é pessoal, único, diferenciado. Nesse aspecto incluem-se as memórias ativadas por meio das histórias pessoais, que, ao serem reveladas ou revisitadas, ganham outra dimensão, especialmente quando falamos do universo da criação em suas várias linguagens, entre elas, a do design.

\subsection{Design, memória, ensino-aprendizagem em uma ação interdisciplinar}

A memória seja por meio do resgate das lembranças ou da investigação da maneira de se viver constitui um dos aspectos determinantes para a criação no contemporâneo. Isso ocorre na atualidade porque diante da pluralidade de informações, conhecimentos e técnicas, do desenvolvimento tecnológico acelerado e compartilhamento de informações incessante, o ser humano passou a buscar questões e aspectos que remetam ao que é singular e diferenciado. Podemos perceber que neste caminho as afetividades, emoções e memórias tornam-se essenciais.

Conforme diz a historiadora Dulce Pandolfi "A memória não diz respeito apenas ao passado. Ela é presente e é futuro" (Pandolfi In: Memórias da ditadura, O Globo, 2013). Ou seja, o resgate do passado ajuda a construir o presente e o futuro. A memória retomada, a lembrança vivenciada torna-se presente novamente ao ser resgatada, auxiliando a delinear e a visualizar o futuro e Design diz respeito ao presente e ao futuro que são estruturados a partir do resgate do passado.

No campo do design, começamos a perceber o crescimento e a valorização das ações relacionadas à memória pessoal e a histórias de vida. Então começamos a observar mais atentamente, a pesquisar, coletar dados e informações a respeito de como e por que a memória passava a ser um aspecto presente e que se destacava no campo do design contemporâneo. Por outro lado vivenciávamos uma situação desafiadora e problemática nos processos de orientação de projetos nas disciplinas nas quais atuávamos como docentes responsáveis. Cada vez mais e, a cada nova turma, percebíamos a dificuldade do aluno em lidar com os erros, em não aceitar a experiência e a orientação do professor. A cada negativa ou condução para a correção 
ou melhoria de algo presente no projeto criava-se um grande problema, pois os alunos sentiam-se aviltados pela interferência em suas criações. Choros, crises de depressão, discussões fervorosas tornavam-se uma constante. Nós, em nossa atuação como docente, passamos a nos sentir tocados e incomodados com essa situação, afinal o processo de ensino se constrói em uma relação de reciprocidade que deve, também, ser pautado pela afetividade. Começamos a refletir e a buscar o que poderia ser proposto onde não houvesse a dicotomia "certo e errado" e partimos em busca de uma nova maneira para a atuação no processo de ensino-aprendizagem. Associados a essas reflexões o nosso interesse e a pesquisa a respeito da memória tomava corpo e resolvemos associar essas questões. Afinal, memórias e lembranças, sejam verdadeiras completamente ou inventadas ou, ainda, construídas a partir de uma mistura entre as verdades e as invenções, são sempre certas, não se estabelece espaço para questionamentos ou para padrões pré-estabelecidos. Além disso, o processo de invenção contribuiu de forma significativa para a criação, para a inovação. Somaram-se a todos esses pensamentos o fato de que as memórias auxiliam na afirmação das identidades, ampliam a percepção e as sensibilidades, ajudam a estabelecer a leitura do mundo, da vida e, acima de tudo, a valorizar o que há de mais humano na vida: os sentimentos, as relações com a família, como os amigos, com o outro contribuindo para a compreensão e para a relação com o ser humano.

Retomamos alguns trabalhos de nossa formação universitária a esse respeito e percebemos que seria importante trazer a pesquisa somada às vivências desenvolvidas para o processo de ensino e aprendizagem em sala de aula.

Dessa forma nascia o projeto interdisciplinar "Memórias da minha vida traduzidas em produto editorial", destinado aos alunos do 4을 semestre do curso de Design Gráfico da UNESP de Bauru e envolvendo as disciplinas de Oficina Gráfica, Fotografia, Tipografia e Produção Gráfica e associando as disciplinas realizadas anteriormente pelos alunos no decorrer do curso, de forma que os eixos de formação ocorriam tanto na horizontalidade das disciplinas existentes durante o semestre em curso quanto na verticalidade da formação ocorrida a partir das disciplinas desenvolvidas nos semestres anteriores.

A grande questão que este tipo de trabalho envolve é a de considerar todas as possibilidades e todas as verdades construídas pelo processo de resgate da memória familiar para potencializar a criação e o design autoral.

Cada pessoa tem uma história que é única, permeada por diversas histórias e personagens que constituem uma memória singular. As histórias marcantes na nossa vida, a primeira vez de uma série de fatos são, na verdade, até mais simples de se recordar e as mantemos em nossa memória quase como um exercício contínuo de repetição e fixação, porém, é importante ativarmos a ação de percebermos e nos lembrarmos da vida cotidiana, pois ela, nos gestos, atos e fatos traz enorme potencial com relação às recordações que se constituem em novas experiências e novos conhecimentos.

A proposta é que, a partir do resgate das memórias, das histórias familiares e pessoais, o aluno desenvolva um livro a partir de uma pesquisa sobre quem ele é, suas relações familiares e de amizades, suas lembranças de vida, histórias pessoais, hábitos cotidianos e ritos de passagem que são apresentadas em um texto formulado pelo próprio aluno a partir de um roteiro proposto em sala de aula. Após a fase de levantamentos para a pesquisa, é realizada a escolha do tema norteador do livro, a 
síntese e edição do texto produzido e é desenvolvido o projeto que deve ser contemplado com a criação e seleção dos textos, das imagens, materiais e acabamentos que irão compor o livro. O objetivo principal é relacionar conteúdo e forma, design editorial, de superfície e autoral.

Em paralelo a essas atividades o aluno é colocado em contato com o aprendizado das linguagens e técnicas gráficas e visuais que irão compor o livro, entre elas, monotipias, clichê de barbante, xilogravura, isogravura, linóleo-gravura, serigrafia, estamparia, fotografia, fotograma, tipografia, processos gráficos. Vários suportes são explorados, tais como diferentes tipos de papéis, tecidos, plásticos, madeiras.

Nos últimos anos a produção de livros independentes, artesanais, livros de artista em peças únicas ou em pequenas séries tem sido retomada e tem potencializado um novo mercado, tanto o de pequenas editoras ou ateliês de produção literária artesanal quanto o das feiras desse tipo de produto. Esse tipo de produção tem sido valorizado no Brasil e já ocorrem editais para patrocínio advindos de órgãos culturais estatais.

Portanto, trazer esse tipo de produção para a sala de aula, oficinas e laboratórios de ensino e pesquisa possibilita aos alunos, por meio do processo pedagógico, explorar vários aspectos de importância para sua formação como designer. Primeiro, tomar a consciência do conhecimento sobre si mesmo, as suas origens e relações familiares, ou seja, conhecer sua própria história possibilita assumir o papel de agente na criação e experimentação de processos autorais. Segundo, estabelecer essas relações como referências para sua atuação projetual. Terceiro, abrir a possibilidade de atuar com o segmento de design editorial e de livros autorais, seja em peças únicas, seja em séries. $E$, ainda, criar espaços produtivos com este tipo de produto. $E$, também, criar uma nova história partindo do que foi levantado e pesquisado, mas selecionando conceitos importantes para uma nova criação, como veremos nos exemplos abaixo.

$O$ resultado da proposta tem sido bem aceito pelos alunos que se envolvem no processo, estabelecem e fortalecem relações afetivas tanto com os familiares quanto com os amigos e colegas de classe, resgatam histórias, lembranças, objetos, fotos, textos e outras coisas guardadas que são simbólicas e expressam a sua história de vida. Os resultados obtidos, ao longo desses quatro anos, têm sido muito significativos. Os alunos sentem-se valorizados, acabaram as crises em sala de aula na orientação dos projetos. Além disso, como a maioria encontra-se longe da família que, geralmente mora em outras cidades, esse é um motivo de convivência e interação com os familiares, pois os alunos tem de buscar fotos, ouvir histórias, perguntar e relembrar junto aos seus os fatos de sua infância, de seus ritos de passagem, por exemplo, o que aconteceu com o primeiro dentinho que caiu? Qual era a profissão de seu avô paterno? Como a mãe foi pedida em casamento? Qual foi sua reação ao nascer o irmão mais novo?

Outro aspecto importante a ser destacado é que nessa ação não há certo ou errado, pois todas as histórias desenvolvidas, independente do fato de serem reais ou imaginadas, são corretas e consideradas. A diferença que pode ocorrer no resultado e que norteia a avaliação das disciplinas é o processo de desenvolvimento da proposta e o resultado final do livro. 


\subsection{Livros de Memórias: histórias de vida, histórias de design}

Os melhores resultados desse projeto interdisciplinar são reunidos e expostos em uma mostra permanente na internet, no site Design Contemporâneo (http://www.designcontemporaneo.com.br) . Depois do processo concluído voltar aos resultados e analisá-los como estudos de caso é extremamente significativo, pois ajudam a indicar possiveis redirecionamentos e ordenações necessárias ao desenvolvimento da disciplina e do projeto, bem como a necessidade de inclusão de novos conteúdos teóricos, de facilitação de processos práticos.

Para este artigo selecionamos alguns exemplos, mas existem muitos outros que merecem ser publicados em outras ocasiões. É interessante notar que a partir do tema único (do projeto interdisciplinar) vários enfoques diferenciados são constituídos. Por exemplo, entre as turmas de 2014 e 2015 percebemos a existência dos seguintes enfoques ou recortes temáticos que são a estrutura conceitual e direcionadora do projeto individual. Evidentemente o tema, os enfoques conceituais contem também uma mistura, uma hibridização entre os vários aspectos.

\section{Nome ou sobrenome como temática:}

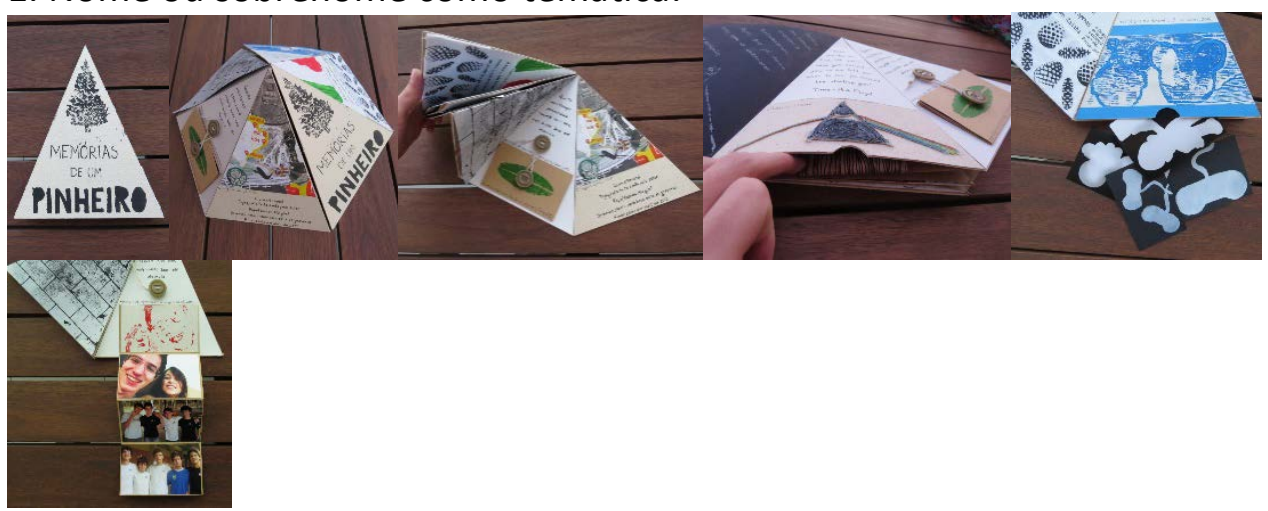

Figura 1 - Livro Memórias de um Pinheiro de Matheus Pegorim Pinheiro, 2015.

Fonte: "Elaborado pelo autor, com base na pesquisa realizada".

2. Expressões artísticas com as quais os alunos se relacionam e que se tornam tema e conceito projetual:

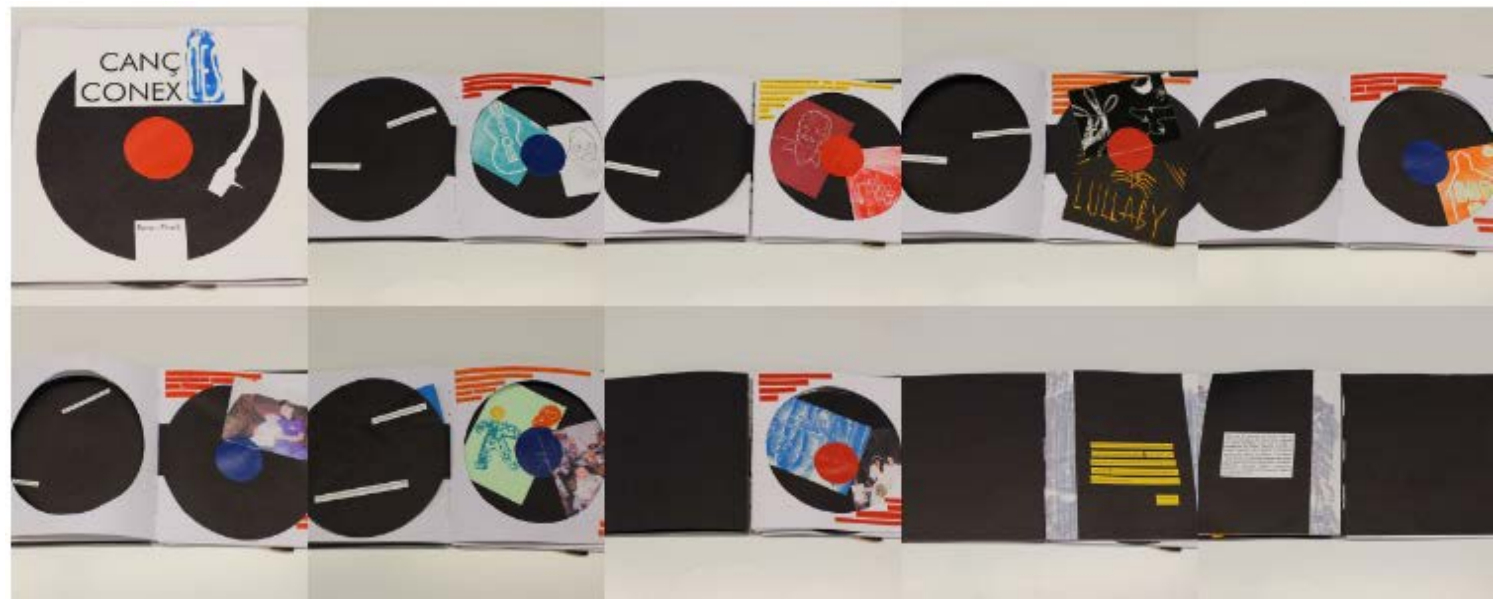

Figura 2 - Livro Canções Conexões de Renan Pinelli, 2014.

Fonte: "Elaborado pelo autor, com base na pesquisa realizada". 
3. A natureza, os jardins e flores:

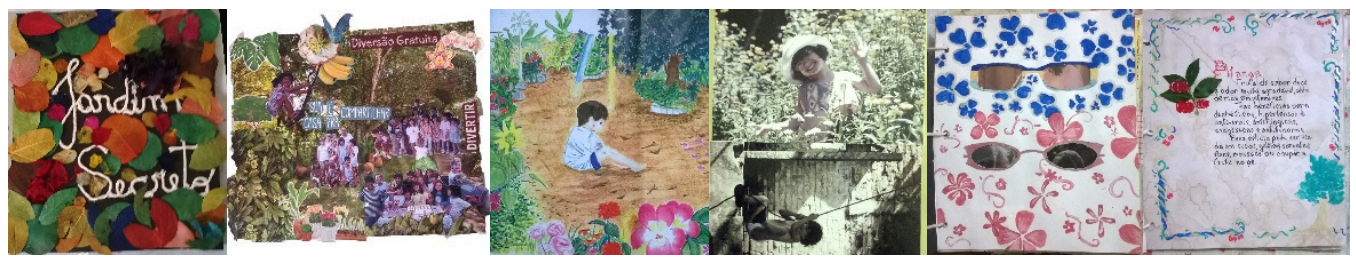

Figura 3 - Livro Jardim Secreto de Sofia Oliveira, 2014.

Fonte: "Elaborado pelo autor, com base na pesquisa realizada".

4. A família e os amigos:



Figura 4 - Livro Pessoas de Giuliana Cecilia Ferrero, 2015.

Fonte: "Elaborado pelo autor, com base na pesquisa realizada".

5. Lembranças da infância e da adolescência:

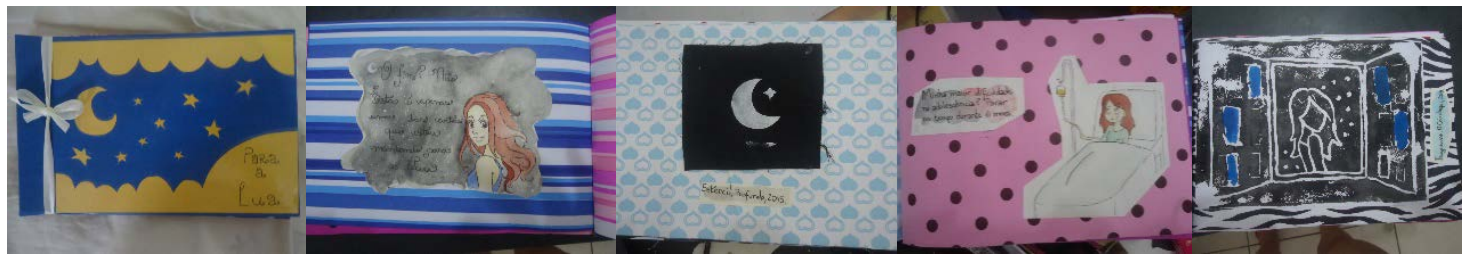

Figura 5 - Livro Para a Lua de Selene Kanagawa de Siqueira Vieira, 2015.

Fonte: "Elaborado pelo autor, com base na pesquisa realizada".

6. Reflexões e sentimentos sobre si mesmo e sobre a sua própria vida:

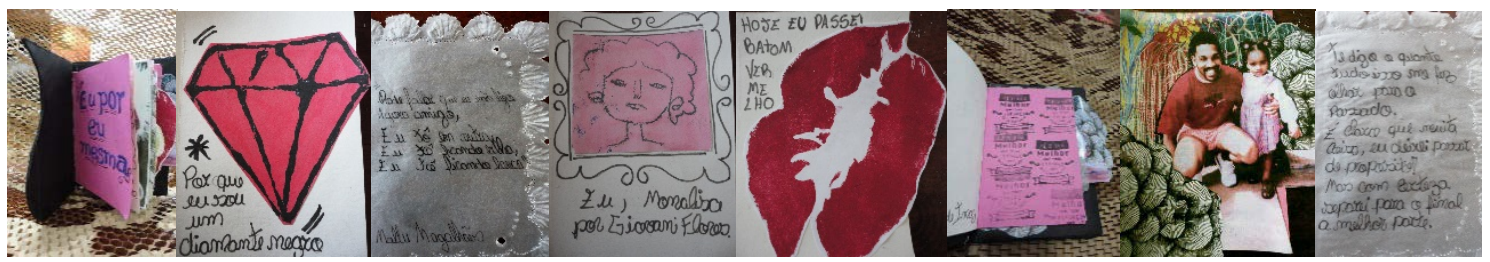

Figura 6 - Livro Eu por Eu Mesma de Carolina Cristina Souza, 2015.

Fonte: "Elaborado pelo autor, com base na pesquisa realizada". 
7. Resgate das memórias como tema central:

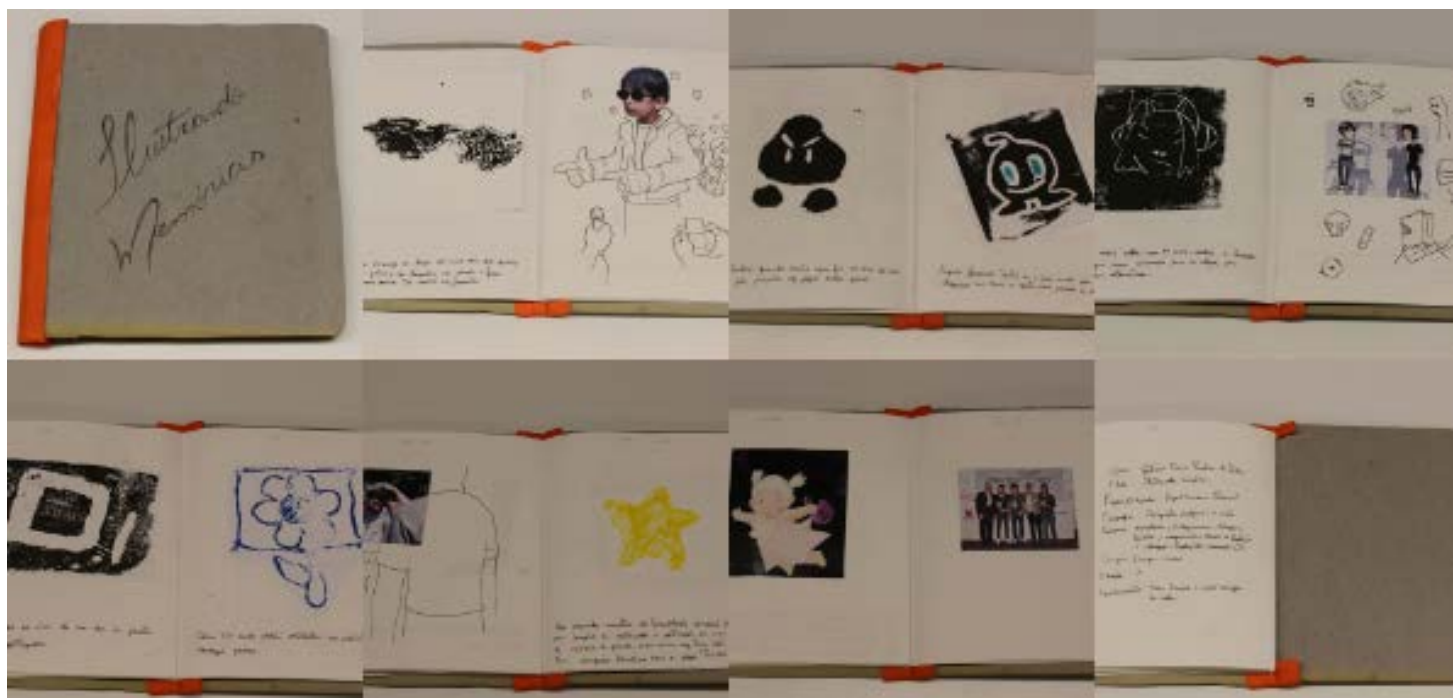

Figura 7 - Livro llustrando Memórias de Gustavo Cerino, 2014.

Fonte: "Elaborado pelo autor, com base na pesquisa realizada".

Recorrenteza é o título do livro de Marina Jardim Tarozzo. O processo de envolvimento da aluna foi intenso, ao pensar e repensar sobre si mesma trouxe suas histórias familiares, aprendizados e observações pessoais com intensa coragem e sensibilidade. Relacionou a vida a um rio em uma síntese estabelecida através da fluidez. Os momentos e as passagens da vida foram relacionados à nascente, afluentes e foz. O envolvimento e a qualidade do processo e do resultado final foram tão intensos que convidamos a própria aluna a descrever o seu processo e o seu livro que se encontra no texto abaixo.


Figura 8 - Processo de desenvolvimento do livro Recorrenteza, de Marina Jardim Tarozzo, 2016.

Fonte: Acervo do Acervo do Laboratório de Pesquisa, Extensão e Ensino em Design Contemporâneo, FAAC- UNESP. Fotos de Marina Jardim Tarozzo.

\subsection{Palavras de Marina}

Como resultado final, memórias pessoais corridas, estampadas e organizadas com papel, tinta e outros materiais inusitados. Porém, o exercício pedido em sala para a disciplina de Oficina Gráfica é muito mais complexo e vai além das páginas do livro.

O pesquisar memórias e a atividade de transcrevê-las através de estampas, signos e cores, que diferem um pouco da leitura de uma fotografia ou outro tipo de imagem, é intenso e demanda muita dedicação e maturidade.

Como definir sua história pessoal em um tema? Como uniformizar algo que parece tão disperso e confuso? 
No caso do meu projeto, o tema central, que me possibilitou conectar todas as minhas experiências e memórias, foi caracterizado e denominado como fluidez. Assim, o título ficou "Recorrenteza". O livro foi dividido em três capítulos, o primeiro discorria sobre o meu nascimento e origem, sendo assim denominado como "NASCENTE'. Já no segundo, procurei concentrar memórias mais dispersas, que não necessariamente possuem uma linearidade, porém são particularidades que me compõe como quem eu sou, como Marina. Assim, o apelidei de "AFLUENTES". E tentando concluir algo que não necessariamente possui um fim, pois a vida continua, o último capítulo chamei de "FOZ", onde dialoguei sobre a saída de casa, as viagens e experiências mais recentes que me parecem encaminhar para o que possa acontecer no futuro.



Figura 9 - Livro Recorrenteza, de Marina Jardim Tarozzo, 2016.

Fonte: Acervo do Laboratório de Pesquisa, Extensão e Ensino em Design Contemporâneo, FAAC- UNESP. Fotos de Marina Jardim Tarozzo.

O tema da fluidez e a linearidade do correr de um rio, também deveria permear o formato do livro, influenciando o modo de leitura. Assim, optei por deixar o livro em formato retangular, e a estrutura de sanfona, de maneira que todas as memórias que estejam ali dentro possam ser observadas de uma vez só, ao abrir o livro e esticá-lo sobre alguma superfície.
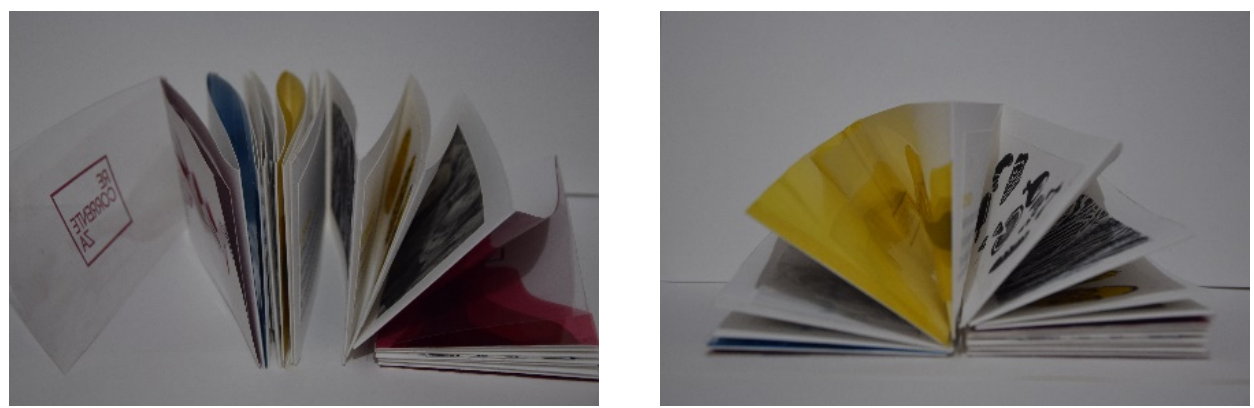

Figura 10 - Livro Recorrenteza, de Marina Jardim Tarozzo, 2016.

Fonte: Acervo do Acervo do Laboratório de Pesquisa, Extensão e Ensino em Design Contemporâneo, FAAC- UNESP. Fotos de Marina Jardim Tarozzo.

É um projeto pesado, que envolve uma busca pessoal profunda; porém traz a todos os alunos que tem a possibilidade de fazê-lo, uma maturidade em termos metodológicos e projetuais, que poucas disciplinas proporcionam aos estudantes de 
Design. Uma carga que acaba sendo levada não apenas em todo o decorrer do curso de graduação, mas parece permear toda a carreira profissional.

\section{CONCLUSÃO}

Os exemplos que trouxemos nesse artigo indicam a atuação dos designers na contemporaneidade onde a memória, histórias pessoais, inventividade e sensibilidade caminham juntas na construção de objetos que, um dia, construíram novas e outras histórias. Apontam também quanto os alunos em processo de formação, destacam a importância da memória que, ao ser resgatada a partir das histórias familiares e das lembranças, passa a conscientizar, ajudar ou retomar a construção das histórias pessoais. Nesse processo, o conhecimento é explorado tornando essas memórias vivas novamente pela reativação das lembranças. Essa ação também envolve o autoconhecimento, a consciência de si mesmo, fato que é de relevância para todos aqueles que trabalham com criação, pois sabemos que a única coisa que pertence verdadeiramente ao homem é a sua história e a sua memória que vivem além dele mesmo e que constroem histórias únicas.

Conhecer-se, saber de onde veio, quais são os seus companheiros de vida, lidar com sentimentos é ter o poder de construir sua identidade, fazer escolhas e valorizar o sensível e o simbólico no decorrer da vida pessoal e profissional e poder ver o mundo a partir de diferentes ângulos e perspectivas, reconhecendo no outro um pouco de si mesmo.

O processo que envolve o resgate de memórias também colabora para entender o outro, o ser humano, os sujeitos com os quais lidamos, especialmente em uma profissão como a de designer, que tem como premissa básica a relação humana e a busca de uma sociedade melhor.

\section{REFERÊNCIAS}

ABBAGNANO, Nicola. Dicionário de Filosofia. SP: Martins Fontes, 1998.

BERGSON, Henri. Matéria e memória: ensaio sobre a relação do corpo com o espírito. Tradução Paulo Neves. São Paulo: Martins Fontes, 1999.

BOSI, Ecléa. O Tempo Vivo da Memória: Ensaios de Psicologia Social. São Paulo: Ateliê Editorial, 2003.

CÉSAR ADES. A memória partilhada- Resenha de: BOSI, ECLÉA. (2003). O Tempo Vivo da Memória: Ensaios de Psicologia Social. São Paulo: Ateliê Editorial. Disponível na internet por http em: http://www.scielo.br/scielo.php?pid=S010365642004000200012\&script=sci_arttext. Acesso em 10 out. 2014.

COUTO, Rita Maria de Souza. Fragmentação do conhecimento ou interdisciplinaridade: ainda um dilema contemporâneo? In: Revista Faac, Bauru, v. 1, n. 1, p. 11-19, abr./set. 2011.

MILTON HATOUM. O progresso que engana. 8.11.2013. In: O Estado de SP, Caderno 2, C8, 2013.

HOBSBAWM, E. J. A Era dos Extremos - o breve século XX. São Paulo: Companhia das Letras, 2008. 
MARQUEZ, Gabriel García. Viver para contar. Rio de Janeiro: Record, 2003.

Mostra Memórias 2014 e 2015. Disponível na internet por http em <http://www.designcontemporaneo.com.br/2014/12/10/mostra-memorias/>. Acesso em 10 fev. 2016.

MOURA, M. (org.). Design Brasileiro Contemporâneo: reflexões. São Paulo: Estação das Letras e Cores, 2014.

PANDOLFI, Dulce In: RICARDO NOBLAT. Memórias da ditadura: 'Servi de cobaia para uma aula de tortura'. 05.06.2013. Disponível na internet por http em <http://noblat.oglobo.globo.com/documentos/noticia/2013/06/memorias-daditadura-servi-de-cobaia-para-uma-aula-de-tortura-499064.html>. Acesso em 10 de nov 2015.

POYNOR, R. No Mas Normas diseño gráfico posmoderno. México: GG, 2003.

TELLES, Lygia Fagundes. Invenção e Memória. São Paulo: Companhia das Letras, 2009. 